International Journal of Environmental Research and

\title{
Chinese Pediatrician Attitudes and Practices Regarding Child Exposure to Secondhand Smoke (SHS) and Clinical Efforts against SHS Exposure
}

\section{Kaiyong Huang ${ }^{1}$, Abu S. Abdullah 2,3,4,*, Haiying Huo ${ }^{1}$, Jing Liao 5 , Li Yang 1,*, Zhiyong Zhang ${ }^{1}$, Hailian Chen ${ }^{1}$, Guangmin Nong ${ }^{5}$ and Jonathan P. Winickoff 6}

1 School of Public Health, Guangxi Medical University, Nanning, Guangxi 530021, China;

E-Mails: huangka0319@sina.com (K.H.); huohy0117@126.com (H.H.);rpazz@163.com (Z.Z.); chlq869007621@163.com (H.C.)

2 Global Health Program, Duke Kunshan University, Kunshan, Jiangsu 215347, China

3 Duke Global Health Institute, Duke University, Durham, NC 27708, USA

4 School of Medicine, Boston Medical Center, Boston University, Boston, MA 02118, USA

5 Department of Pediatrics, The First Affiliated Hospital of Guangxi Medical University, Nanning, Guangxi 530021, China; E-Mails: gxlmd@126.com (J.L.); ngm8525@hotmail.com (G.N.)

6 Massachusetts General Hospital (MGH) Center for Child and Adolescent Health Research and Policy, Harvard Medical School, Boston, MA 02114, USA; E-Mail: jwinickoff@partners.org

* Authors to whom correspondence should be addressed;

E-Mails: asm.abdullah@graduate.hku.hk (A.S.A.); yangli8290@hotmail.com (L.Y.); Tel.: +86-512-3665-7090 (A.S.A.); +86-771-535-8805 (L.Y.); Fax: +86-512-3665-7090 (A.S.A.); $+86-771-535-0642$ (L.Y.).

Academic Editor: Paul B. Tchounwou

Received: 25 February 2015 / Accepted: 28 April 2015 / Published: 8 May 2015

Abstract: Background: Secondhand Smoke (SHS) exposure is a leading cause of childhood illness and premature death. Pediatricians play an important role in helping parents to quit smoking and reducing children's SHS exposure. This study examined Chinese pediatricians' attitudes and practices regarding children's exposure to SHS and clinical efforts against SHS exposure. Methods: A cross-sectional survey of pediatricians was conducted in thirteen conveniently selected hospitals in southern China, during September to December 2013. Five hundred and four pediatricians completed self-administered questionnaires with a response rate of $92 \% . \chi^{2}$ tests were used to compare categorical variables differences between smokers 
and non-smokers and other categorical variables. Results: Pediatricians thought that the key barriers to encouraging parents to quit smoking were: lack of professional training (94\%), lack of time (84\%), resistance to discussions about smoking (77\%). 94\% of the pediatricians agreed that smoking in enclosed public places should be prohibited and more than $70 \%$ agreed that smoking should not be allowed in any indoor places and in cars. Most of the pediatricians thought that their current knowledge on helping people to quit smoking and SHS exposure reduction counseling was insufficient. Conclusions: Many Chinese pediatricians did not have adequate knowledge about smoking and SHS, and many lacked confidence about giving cessation or SHS exposure reduction counseling to smoking parents. Lack of professional training and time were the most important barriers to help parents quit smoking among the Chinese pediatricians. Intensified efforts are called for to provide the necessary professional training and increase pediatricians' participation in the training.

Keywords: pediatrician; secondhand smoke; exposure; smoking cessation

\section{Introduction}

The tobacco epidemic is one of the biggest public health threats the World is facing, killing approximately 6 million people each year. More than 5 million of these deaths are as a result of direct tobacco use, while more than 600,000 are attributable to Secondhand Smoke (SHS) exposure [1]. $80 \%$ of the deaths occur in low- and middle-income countries, and the death toll could rise to more than 8 million per year by 2030 if the current trend of increasing global tobacco use remains unaddressed [1-3]. China, a middle-income country, is the World's largest producer and consumer of tobacco, with 350 million smokers [4], and has almost 740 million non-smokers passively exposed to SHS, including 180 million children under 15 years old [5,6]. Nearly 100,000 deaths related to SHS exposure occur in China annually [5]. There is no known safe level of SHS exposure [7]. It is reported that children exposed to SHS have higher rates of lower respiratory illness, asthma and asthma exacerbations, coughs, middle ear infections, hospitalizations, cardiovascular disease and sudden infant death syndrome $[8,9]$.

Smoking bans were implemented in public areas including workplaces, government buildings, public transportation, healthcare facilities, supermarkets, schools, bars and restaurants in 2010 to reduce the prevalence of SHS exposure in China [5]. However, SHS exposure at home which is often neglected is the primary source of exposure to tobacco smoke for children [10,11]. In 2010, the prevalence of SHS exposure at home in China was 67.3\% [5], much higher than the United States [12], Mexico and India [13].

Smoking cessation is a priority for reducing the harm and burden caused by smoking-attributable diseases $[14,15]$. There is the modeling effect on children whose parents smoke at home, and parental smoking is a potent indicator of which children will become adult smokers [16]. Among the physicians group, pediatricians can address both SHS exposure to children and parental smoking cessation and therefore are in a critical position to implement parental tobacco control programs. Pediatricians believe that exposure to SHS is harmful to children's health and have expressed opposition to SHS exposure among children $[17,18]$. In the United States, pediatricians are encouraged by the 
U.S. Surgeon General and the American Academy of Pediatrics (AAP) to directly address SHS with parents and provide guidance on smoking cessation [19].

In many studies on physicians, beliefs regarding the effectiveness of counseling and medications for smoking cessation and reducing SHS are different. For example, a systematic review indicated that the majority of general practitioners and family physicians thought discussing smoking cessation with their patients were ineffective [20]. Another systematic review showed that when physicians provided smoking cessation advice for patients it significantly increased the odds of quitting smoking [21]. However, pediatricians have yet to fully embrace their role in helping parents quit smoking and helping children reduce SHS exposure [19]. No study has been conducted on pediatricians' attitudes and practices about children SHS exposure in China. To explore Chinese pediatricians' attitudes and practices regarding children exposure to SHS and clinical effort against SHS exposure, we conducted a quantitative study on pediatricians residing in southern China.

\section{Methods}

\subsection{Design and Sample}

A cross-sectional survey of pediatricians was conducted from September to December 2013 to assess Chinese pediatricians' attitudes and practices regarding children exposure to SHS and clinical efforts against SHS exposure. A standardized Chinese language self-administered questionnaire was used to collect data from 550 pediatricians working in the thirteen hospitals - twelve grade III and one grade (I) - selected conveniently in four major cities (Nanning, Liuzhou, Guilin and Qinzhou) of Guangxi Province (a southern Chinese province), the People's Republic of China. Questionnaires were distributed to each pediatrician working in the selected hospitals by the directors. Pediatricians were requested to complete all the questions on the questionnaire, seal the questionnaire in an envelope and drop it in a designated box kept in the general office of the department. Our study coordinator then collected the sealed questionnaires from each of the directors and checked all questionnaires. If questionnaires had any unclear answers, unfinished questions, and/or logistic errors, our study coordinator would contact the individual pediatrician by telephone or interview them face to face. To compensate for their time, each participant was given a cash amount of RMB 100 (\$15). Our study protocols were approved by the Ethical Committee of Guangxi Medical University and we received informed consent from all individuals who agreed to participate in the study.

\subsection{Measures}

The questionnaire was developed with reference to the questionnaires previously used by the investigators team in the United States [22] and in China [23]. The questionnaire included questions on the following domains: demographic and other characteristics, barriers to smoking cessation counseling, attitudes and practices toward tobacco use and SHS exposure, and knowledge of SHS exposure.

We collected demographic and other information on gender, age, physician type, number of years studied at medical school, smoking behavior (smoker, non-smoker), and other questions on "Have you ever received any formal training in smoking cessation?" (Yes or No), "Have you read China's smoking cessation guidelines?" (Yes, No, and Never heard about it), "Have you read international smoking 
cessation guidelines?" (Yes, No, and Never heard about it). We defined "smoker" as those who smoked at the time of the survey, and defined "non-smoker" as those who never smoked or quitted smoking at the time of survey [11]. Pediatricians' perceived barriers to the delivery of smoking cessation counseling to smoking parents of children were assessed by asking seven questions (Table S1), with response categories of "Major Barrier, Moderate Barrier, Minor Barrier and Not a Barrier". For analysis, responses were condensed to two categories of "Major Barrier/Moderate Barrier", and "Minor Barrier/Not a Barrier". Questions asked in other domains of the questionnaire and the related response categories are available in Table S1.

\subsection{Analyses}

Two members of the research team coded each questionnaire and entered all data with Epidata 3.1, and then made a data consistency check. $\chi^{2}$ tests were used to compare categorical variables differences between smoker and non-smoker. A $p$-value of $<0.05$ (two-tailed) was considered statistically significant. We used SPSS version 13.0 to conduct all statistical analyses.

\section{Results}

\subsection{Demographic and Other Characteristics Information}

A total of 504 participants successfully completed the questionnaires, with a response rate of $92 \%(504 / 550)$. Of the respondents, $64 \%$ were female with $74 \%$ being between the ages of 20 and 40 , and $75 \%$ were resident and attending physicians, $77 \%$ of the participants had received 5 years of education in medical school and $17 \%$ smoked at the time of the survey. $81 \%$ of the samples hadn't received formal training in smoking cessation, and $64 \%$ of all pediatricians hadn't read China's smoking cessation guidelines, with $21 \%$ having never heard about them. Three hundred and fifty nine participants (71\%) hadn't read any international smoking cessation guidelines, and $22 \%$ had never heard about them (Table 1).

Table 1. Demographic and other characteristics of pediatricians, Guangxi, China 2013 $(\mathrm{n}=504)$.

\begin{tabular}{lcl}
\hline Variables & N & \% \\
\hline Gender & & \\
Male & 182 & 36 \\
Female & 322 & 64 \\
Age & & \\
$20-30$ & 215 & 43 \\
$31-40$ & 159 & 31 \\
$41-50$ & 89 & 18 \\
Above 50 & 41 & 8 \\
Physician type & & \\
Resident Physician & 223 & 45 \\
Attending Physician & 151 & 30 \\
Associate Chief Physician & 88 & 17 \\
Chief Physician & 42 & 8 \\
\hline
\end{tabular}


Table 1. Cont.

\begin{tabular}{lcc}
\hline Variables & $\mathbf{N}$ & $\%$ \\
\hline Number of years studied at medical school & \\
\hline 5 Years & 388 & 77 \\
\hline More than 5 years & 116 & 23 \\
\hline Smoking status & \multicolumn{1}{l}{} \\
\hline Current smoker & 82 & 16 \\
\hline Non-smoker & 422 & 84 \\
\hline Received formal training in smoking cessation & \\
\hline No & 399 & 81 \\
\hline Yes & 96 & 19 \\
\hline Have read China's smoking cessation guidelines \\
\hline No & 322 & 64 \\
\hline Yes & 77 & 15 \\
\hline Never heard about it & 105 & 21 \\
\hline Have read international smoking cessation & guidelines \\
\hline No & 359 & 71 \\
\hline Yes & 36 & 7 \\
\hline Never heard about it & 109 & 22 \\
\hline \multicolumn{4}{l}{}
\end{tabular}

\subsection{Barriers to Smoking Cessation}

Most of the pediatricians perceived the key barriers to be: "Parents are resistant to discuss about smoking" (77\%), "It is hard to find a time to talk with parents" (84\%), "Lack of professional training in the area of tobacco cessation counseling" (94\%), "Lack of a standard of care requiring pediatricians to provide smoking cessation or SHS exposure reduction intervention" (64\%), "It is hard to make system changes that would support parental smoking cessation at our hospital" (76\%), "Not convinced that advice and/or available therapies would work" (61\%) were the barriers to the delivery of smoking cessation counseling to smoking parents of children (as shown in Table 2). However, when comparing the differences of all the perceived barriers between smokers and non-smokers, "Lack of professional training in the area of tobacco cessation counseling" was the only variable that showed a significant difference $(p<0.001) .98 \%$ of the non-smokers compared to $65 \%$ of smokers perceived that lack of professional training was a barrier to provide smoking cessation service to children's smoking parents (Table 2).

Table 2. Pediatricians' perceived barriers to the delivery of smoking cessation counseling to smoking parents of children by smoking status.

\begin{tabular}{|c|c|c|c|c|}
\hline Variables & $\begin{array}{l}\text { All Respondents } \\
(\mathrm{N}=504) \\
\text { Major/Moderate } \\
\text { Barrier } \\
\text { N (\%) }\end{array}$ & $\begin{array}{l}\text { Smoker } \\
(\mathrm{N} 1=82) \\
\text { Major/Moderate } \\
\text { Barrier } \\
\text { N1 (\%) }\end{array}$ & $\begin{array}{l}\text { Non-Smoker } \\
(\mathrm{N} 2=422) \\
\text { Major/Moderate } \\
\text { Barrier } \\
\text { N2 (\%) }\end{array}$ & $p$-Value \\
\hline $\begin{array}{l}\text { Parents are resistant to } \\
\text { discussion about smoking }\end{array}$ & $390(77)$ & $62(76)$ & $328(78)$ & 0.675 \\
\hline $\begin{array}{l}\text { It is hard to find a time to } \\
\text { talk with parents }\end{array}$ & $422(84)$ & $65(79)$ & $357(84)$ & 0.232 \\
\hline
\end{tabular}


Table 2. Cont.

\begin{tabular}{|c|c|c|c|c|}
\hline Variables & $\begin{array}{l}\text { All Respondents } \\
(\mathbf{N}=504) \\
\text { Major/Moderate } \\
\text { Barrier } \\
\text { N (\%) }\end{array}$ & $\begin{array}{l}\text { Smoker } \\
(\mathrm{N} 1=82) \\
\text { Major/Moderate } \\
\text { Barrier } \\
\text { N1 (\%) }\end{array}$ & $\begin{array}{l}\text { Non-Smoker } \\
(\mathrm{N} 2=422) \\
\text { Major/Moderate } \\
\text { Barrier } \\
\text { N2 (\%) }\end{array}$ & $p$-Value \\
\hline $\begin{array}{l}\text { Lack of professional training } \\
\text { in the area of tobacco } \\
\text { cessation counseling }\end{array}$ & $455(94) *$ & $40(65) *$ & $415(98) *$ & $<0.001$ \\
\hline $\begin{array}{l}\text { Lack of a standard of care } \\
\text { requiring pediatricians to } \\
\text { provide smoking cessation or } \\
\text { SHS exposure reduction } \\
\text { intervention }\end{array}$ & $321(64)$ & $53(65)$ & $268(64)$ & 0.846 \\
\hline $\begin{array}{l}\text { Lack of insurance coverage } \\
\text { for smoking cessation } \\
\text { medication }\end{array}$ & $279(55)$ & $43(52)$ & $236(56)$ & 0.561 \\
\hline $\begin{array}{l}\text { It is hard to make system } \\
\text { changes that would support } \\
\text { parental smoking cessation at } \\
\text { our hospital }\end{array}$ & $383(76)$ & $63(77)$ & $320(76)$ & 0.846 \\
\hline $\begin{array}{l}\text { Not convinced that advice } \\
\text { and/or available therapies } \\
\text { would work }\end{array}$ & $306(61)$ & $53(65)$ & $253(60)$ & 0.427 \\
\hline
\end{tabular}

\subsection{Attitudes and Practices}

Table 3 provides results for the pediatricians' attitudes and practices regarding children's exposure to SHS and clinical efforts against SHS exposure. Most of the respondents have good knowledge about SHS. Compared to the pediatricians who were smokers, the non-smokers were more likely to agree that SHS causes children's pulmonary disease $(p=0.028)$, SHS causes asthma in children $(p=0.031)$, and paternal smoking increases the risk of lower respiratory tract illnesses such as pneumonia in exposed children $(p<0.001)$.

Of the 504 pediatricians, $94 \%$ expressed the opinion that smoking in enclosed public places should be prohibited. In addition, more than $70 \%$ of the participants agreed smoking should not be allowed in any indoor room and in cars (non-smokers were more likely to agree to these issues $(p<0.001$; $p<0.001)$ ) (Table 3).

More than $79 \%$ of the respondents agreed that pediatricians should routinely ask their patients' parents about their smoking habits and advise the smoking parents to quit smoking (non-smokers were more likely to agree $(p<0.001$, and $p<0.05) .56 \%$ of the participants thought pediatricians can help patients' parents stop smoking, $60 \%$ believed physician counseling for smoking cessation was effective, and $53 \%$ believed pharmacological products were effective in helping people quit smoking. 
However, 51\% expressed the opinion that smoking cessation counseling is not an efficient use of their time. Nearly $93 \%$ agree that physicians should advise parents to avoid smoking around children and that they shouldn't smoke in front of their patients.

On average, $51 \%$ of the pediatricians admitted they could find resources to help patient's parents to quit smoking in their hospital, but $62 \%$ didn't know the best strategies for helping patients' parents to stop smoking. In addition, only $17 \%$ of the pediatricians thought their current knowledge was sufficient for helping patients' parents to stop smoking, and 30\% thought their current knowledge was sufficient for helping parents to reduce children's' SHS exposure. More than $61 \%$ were not familiar with the guidelines for smoking cessation, and only $16 \%$ could assess a smoker's different stages of readiness to quit.

Table 3. Attitudes and practices regarding child exposure to SHS and clinical effort against SHS exposure by smoking status.

\begin{tabular}{|c|c|c|c|c|}
\hline Variables & $\begin{array}{l}\text { All Respondents } \\
(\mathrm{N}=504) \\
\text { Agree } \\
\mathrm{N}(\%)\end{array}$ & $\begin{array}{l}\text { Smoker } \\
(\mathrm{N} 1=82) \\
\text { Agree } \\
\text { N1 }(\%)\end{array}$ & $\begin{array}{l}\text { Non-Smoker } \\
(\mathrm{N} 2=422) \\
\text { Agree } \\
\text { N2 }(\%)\end{array}$ & $p$-Value \\
\hline \multicolumn{5}{|l|}{ Knowledge about SHS } \\
\hline $\begin{array}{l}\text { SHS causes Sudden Infant } \\
\text { Death Syndrome }\end{array}$ & $336(67)$ & $59(72)$ & $277(66)$ & 0.267 \\
\hline SHS causes adult lung cancer & $487(97)$ & $78(95)$ & $409(97)$ & 0.681 \\
\hline SHS causes adult heart disease & $392(78)$ & $64(78)$ & $328(78)$ & 0.949 \\
\hline SHS causes bronchitis & $474(94)$ & $77(94)$ & $397(94)$ & 0.952 \\
\hline $\begin{array}{l}\text { SHS causes children's } \\
\text { pulmonary disease }\end{array}$ & $491(97)$ & $77(94)$ & $414(98)$ & 0.028 \\
\hline SHS causes asthma in children & $487(97)$ & $76(93)$ & $411(97)$ & 0.031 \\
\hline $\begin{array}{l}\text { SHS causes respiratory infections in } \\
\text { children }\end{array}$ & $465(92)$ & $73(89)$ & $392(93)$ & 0.230 \\
\hline $\begin{array}{l}\text { Breathing air in a room today where } \\
\text { people smoked yesterday can harm the } \\
\text { health of infants and children }\end{array}$ & $368(73)$ & $60(73)$ & $308(73)$ & 0.972 \\
\hline $\begin{array}{l}\text { Paternal smoking increases the risk of } \\
\text { lower respiratory tract illnesses such as } \\
\text { pneumonia in exposed children }\end{array}$ & $458(91)$ & $62(76)$ & $396(94)$ & $<0.001$ \\
\hline \multicolumn{5}{|l|}{ Support for smoking bans } \\
\hline $\begin{array}{l}\text { Smoking in enclosed public places } \\
\text { should be prohibited }\end{array}$ & $476(94)$ & $75(91)$ & $401(95)$ & 0.198 \\
\hline $\begin{array}{l}\text { Smoking is not allowed in any } \\
\text { indoor room }\end{array}$ & $354(70)$ & $42(51)$ & $312(74)$ & $<0.001$ \\
\hline Smoking is not allowed in car & $441(88)$ & $61(74)$ & $380(90)$ & $<0.001$ \\
\hline \multicolumn{5}{|c|}{ Support for clinical effort against SHS exposure } \\
\hline $\begin{array}{l}\text { Pediatricians can help patients' parents } \\
\text { to stop smoking }\end{array}$ & $282(56)$ & $47(57)$ & $235(56)$ & 0.786 \\
\hline $\begin{array}{l}\text { Smoking cessation counseling is not an } \\
\text { efficient use of my time }\end{array}$ & $256(51)$ & $47(57)$ & $209(50)$ & 0.197 \\
\hline $\begin{array}{l}\text { Beliefs regarding effectiveness of } \\
\text { physician counseling for } \\
\text { smoking cessation }\end{array}$ & $304(60)$ & $51(62)$ & $253(60)$ & 0.704 \\
\hline
\end{tabular}


Table 3. Cont.

\begin{tabular}{|c|c|c|c|c|}
\hline Variables & $\begin{array}{l}\text { All Respondents } \\
(\mathrm{N}=504) \\
\text { Agree } \\
\mathbf{N}(\%)\end{array}$ & $\begin{array}{l}\text { Smoker } \\
(\mathrm{N} 1=82) \\
\text { Agree } \\
\text { N1 }(\%) \\
\end{array}$ & $\begin{array}{l}\text { Non-Smoker } \\
(\mathrm{N} 2=422) \\
\text { Agree } \\
\text { N2 }(\%)\end{array}$ & $p$-Value \\
\hline $\begin{array}{l}\text { It is easy for me to find resources in my } \\
\text { hospital to help my patient's parents to } \\
\text { quit smoking }\end{array}$ & $256(51)$ & $48(58)$ & $208(49)$ & 0.125 \\
\hline $\begin{array}{l}\text { Physicians should not smoke in front of } \\
\text { their patients }\end{array}$ & $471(93)$ & $74(90)$ & 397 (94) & 0.199 \\
\hline $\begin{array}{l}\text { Advise patients who smoke to avoid } \\
\text { smoking around children }\end{array}$ & $469(93)$ & $74(90)$ & 395 (94) & 0.274 \\
\hline $\begin{array}{l}\text { Routinely ask about their patients } \\
\text { smoking habits }\end{array}$ & $425(84)$ & $54(66)$ & $371(88)$ & $<0.001$ \\
\hline $\begin{array}{l}\text { Routinely advise their smoking patients } \\
\text { to quit smoking }\end{array}$ & $398(79)$ & $57(69)$ & $341(81)$ & 0.022 \\
\hline \multicolumn{5}{|l|}{ Attitudes towards counseling and treatment } \\
\hline $\begin{array}{l}\text { I am not familiar with the guidelines for } \\
\text { stop smoking }\end{array}$ & $309(61)$ & $49(60)$ & $260(62)$ & 0.752 \\
\hline $\begin{array}{l}\text { I am unaware of the best strategies for } \\
\text { helping my patients' parents to stop } \\
\text { smoking }\end{array}$ & $313(62)$ & $51(62)$ & $262(62)$ & 0.985 \\
\hline $\begin{array}{l}\text { Pharmacological products are effective } \\
\text { in helping people quit smoking }\end{array}$ & $266(53)$ & $42(51)$ & $224(53)$ & 0.757 \\
\hline $\begin{array}{l}\text { My current knowledge is sufficient for } \\
\text { helping parents to reduce SHS exposure } \\
\text { to children }\end{array}$ & $151(30)$ & $23(28)$ & $128(30)$ & 0.680 \\
\hline $\begin{array}{l}\text { My current knowledge is sufficient for } \\
\text { helping patients to stop smoking }\end{array}$ & $87(17)$ & $15(18)$ & $72(17)$ & 0.787 \\
\hline $\begin{array}{l}\text { I can assess a smoker's different stages } \\
\text { of readiness to quit }\end{array}$ & $82(16)$ & $12(15)$ & $70(17)$ & 0.661 \\
\hline
\end{tabular}

\section{Discussion}

To the best of our knowledge, this cross-sectional survey is the first study on pediatrician attitudes and practices regarding child exposure to SHS and clinical efforts against SHS exposure in China. The findings suggest that pediatricians should participate in formal training on addressing parental smoking to reduce children's SHS exposure from parental smoking. For example, our findings showed that $81 \%$ of the pediatricians didn't receive formal training on smoking cessation, and 94\% thought lack of professional training was a barrier to the delivery of smoking cessation counseling to smoking parents of children. Similar barriers have also been reported in other studies [17,19,24]. The lack of efficient and effective training might be one reason why pediatricians rarely implement effective children's SHS exposure reduction interventions with smoking parents [24,25]. Similarly, other studies [17,19,24,26], have shown lack of time to talk with parents as another key barrier to reducing SHS exposure to children and promoting smoking cessation counseling. Researchers have indicated pediatrician's provision of a brief advice regarding children's exposure to SHS as an effective first step to make children' parents quit smoking [27,28]. A national survey of pediatric nurses in the United States showed that parents' resistance 
to discussions about smoking was one of the most common barriers to counseling parent [29], and we obtained a similar result in $77 \%$ of all the pediatricians.

Earlier research studies reported that physicians who were nonsmokers were more likely to support complete smoking ban at home [11,28], possess better knowledge about the hazards of smoking [23], provide smoking cessation advise [23,29,30], and believe that smoking cessation counseling is effective to promote smoking cessation [17,23]. In this study, most of the respondents had good knowledge about SHS, with non-smoking pediatricians reporting better results than smokers on certain issues. Possible explanations may be that the non-smoking pediatricians knew more about the dangers of smoking, SHS exposure, and health consequences of smoking to themselves and others, and, hence, refrained from smoking. This underscores the need to increase knowledge about the harms of smoking and SHS among the pediatricians. Most of the respondents supported smoking bans in enclosed public places, indoor rooms and cars, with the non-smoker more likely to agree to issues of "Smoking is not allowed in any indoor room" and "Smoking is not allowed in cars". Consistent with the findings of an earlier study among Chinese physicians [29], smoker and non-smoker physicians did not differ significantly $(p>0.05)$ in their knowledge about the fact that SHS causes sudden infant death syndrome or SHS causes adult lung disease or heart disease. Besides examining the differences according to the smoking status, we have also examined pediatrician's attitudes and practices by gender, age group, physician type and whether they had received any tobacco control training. However, we did not find any significant differences in these categorical analyses (data not shown).

Evidence suggests that counseling [31] and cessation medications [32,33] are effective for smoking cessation. Lately, a study also reported that providers' self-confidence on tobacco intervention may improve the frequency of environmental tobacco smoke exposure related actions [19]. Our study found that over 50\% of the pediatricians were confident that pediatricians can help patients' parents to quit smoking, and believed physician counseling and pharmacological products were effective in helping smokers quit smoking, which was positive and useful information supporting the clinical efforts against SHS exposure. In our study, more than $79 \%$ of the pediatricians agreed that they should routinely ask their patients about their smoking habits and advise them to quit smoking, with the pediatricians who were non-smokers more likely agreeing to these issues compared to the smokers. However, for the reasons of lack of time, training, and resources, most of the pediatricians didn't screen parents smoking status and gave quit smoking advise unless a parent's child was being treated for respiratory diseases [17,19,31]. This is despite the fact that asking parents about their smoking habits and giving simple smoking cessation intervention would only take the pediatrician about $30 \mathrm{sec}$ to $3 \mathrm{~min}$ [34]. The AAP also indicated that pediatricians should query about patients' tobacco use and exposure, and help smoking parents to quit smoking [35].

Even though many interventions for quitting smoking have been implemented in the United States, $52 \%$ of pediatricians were unaware of the best strategies for helping parents to stop smoking and $51 \%$ reported that it was not easy to find resources in their community to help parents quit [36]. We obtained a similar result with $51 \%$ of the pediatricians saying they could find resources to help patient's parents to quit smoking, but more than $60 \%$ were not familiar with the guidelines for cessation and unaware of the best strategies for stopping smoking. In an earlier study, pediatricians did not have adequate knowledge for helping quit smoking [37]. In our study, few of the pediatricians thought that their current knowledge was sufficient for helping parents to quit smoking (17\%) and to reduce SHS exposure to children (30\%), and only $16 \%$ could assess a smoker's different stages of readiness to quit. 
The insufficient knowledge will most likely be a key barrier to helping parents to quit smoking in China. It is therefore important to enhance the training and publicity about smoking cessation, and implement activities for helping parents to quit smoking.

This study had several limitations. First, the sample may not be representative of the whole pediatrician population in China. Because all the selected hospitals were located in urban area of Guangxi Province, and most of the pediatricians come from grade III hospitals (i.e., the hospitals with best facilities, advanced technologies and resources), therefore, the findings may not be generalizable to other lower grade hospitals (i.e., Grade 1 or Grade II). Secondly, nurses can play an important role in helping parents quit smoking and reduced children SHS exposure, but we didn't investigate pediatric nurses in the current study. To make the findings more generalizable, a follow-up survey may select both pediatricians and nurses from all the three grades of hospitals.

\section{Conclusions}

We found that over one-half of the pediatricians believed the fact that pediatricians can help children's parents quit smoking and believed smoking cessation counseling was effective in helping people quit smoking. However, most of the pediatricians' current knowledge was insufficient for reducing children SHS exposure and helping parents to quit smoking. Lack of professional training and time were the most important barriers to help parents stop smoking. We call for intensified efforts to carry out the needed professional training and increase pediatricians' participation in the training, at the same time, asking about their patients smoking habits and advising their smoking patients to quit smoking routinely.

\section{Acknowledgments}

The authors thank the study participants. This study was supported by a grant (principal investigator: Abu S. Abdullah) from the Flight Attendant Medical Research Institute, Miami, Florida, USA, to the American Academy of Pediatrics (AAP), Julius B. Richmond Center.

\section{Author Contributions}

Kaiyong Huang drafted the manuscript, carried out the acquisition, analysis and interpretation of the data, and approved the final manuscript as submitted. Abu S. Abdullah conceptualized and designed the whole study, supervised and instructed data collection and analysis, reviewed and revised the manuscript, and approved the final manuscript as submitted. Jing Liao coordinated and supervised data collection, carried out the initial analyses. Li Yang and Zhiyong Zhang contributed to the overall design of the study, commented on the data collection instrument, and critically reviewed the manuscript. Jonathan P. Winickoff contributed to the overall design of the study, critically reviewed the manuscript. Guangmin Nong contributed to the overall design of the study and data interpretation. Hailian Chen and Haiying Huo carried out the initial analyses. 


\section{Conflicts of Interest}

The authors declare no conflict of interest.

\section{References}

1. World Health Organization. Tobacco, Fact Sheet. Available online: http://www.who.int/media centre/factsheets/fs339/en/ (accessed on 7 January 2015).

2. Demaio, A.R.; Nehme, J.; Otgontuya, D.; Meyrowitsch, D.W.; Enkhtuya, P. Tobacco smoking in Mongolia: Findings of a national knowledge, attitudes and practices study. BMC Public Health 2014, 14, doi:10.1186/1471-2458-14-213.

3. Nakkash, R.; Lee, K. The tobacco industry's thwarting of marketing restrictions and health warnings in Lebanon. Tob. Control. 2009, 18, 310-316.

4. Yang, G.H.; Ma, J.M.; Liu, N.; Zhou L.N. Smoking and passive smoking in China, 2002. Zhonghua Liu Xing Bing Xue Za Zhi 2005, 26, 77-83. (In Chinese)

5. Global Adult Tobacco Survey (GATS) China 2010 Country Report. Available online: http://www. notc.org.cn/newjcpg/201304/W020121108628365808856.pdf (accessed on 7 January 2015).

6. Liu, Y.; Chen, L. New medical data and leadership on tobacco control in China. Lancet 2011, 377, 1218-1220.

7. Tanski, S.E.; Wilson, K.M. Children and secondhand smoke: Clear evidence for action. Pediatrics 2012, 129, 170-171.

8. The Health Consequences of Involuntary Exposure to Tobacco Smoke: A Report of the Surgeon General; Office on Smoking and Health, Centers for Disease Control and Prevention, Coordinated Center for Health Promotion, U.S. Department of Health and Human Services: Atlanta, GA, USA, 2006.

9. Dana, B. Technical report-secondhand and prenatal tobacco smoke exposure. Pediatrics 2009, 124, 1017-1044.

10. Abdullah, A.S.; Hua, F.; Xia, X.; Hurlburt, S.; Ng, P.; MacLeod, W.; Siegel, M.; Griffiths, S.; Zhang, Z. Second-hand smoke exposure and household smoking bans in Chinese families: A qualitative study. Health Soc. Care Community 2012, 20, 356-364.

11. Wei, X.L.; Zhang, Z.Z.; Song, X.L.; Xu, Y.J.; Wu, W.; Lao, X.Q.; Ma, W.J. Household smoking restrictions related to secondhand smoke exposure in Guangdong, China: A population representative survey. Nicotine Tob. Res. 2014, 16, 390-396.

12. Chen, C.; Burton, T.; Baker, C.L.; Mastey, V.; Mannino, D. Recent trends in exposure to secondhand smoke in the United States population. BMC Public Health 2010, 10, doi:10.1186/1471-2458-10-359.

13. King, B.A.; Mirza, S.A.; Babb, S.D. A cross-country comparison of secondhand smoke exposure among adults: Findings from the Global Adult Tobacco Survey (GATS). Tob. Control. 2013, 22, doi:10.1136/tobaccocontrol-2012-050582.

14. Feng, G.; Jiang, Y.; Li, Q.; Yong, H.H.; Elton-Marshall, T.; Yang, J.; Fong, G.T. Individual-level factors associated with intentions to quit smoking among adult smokers in six cities of China: Findings from the ITC China Survey. Tob. Control 2010, 19, doi:10.1136/tc.2010.037093.

15. Coffield, A.B.; Maciosek, M.V.; McGinnis, J.M.; Harris, J.R.; Caldwell, M.B.; Teutsch, S.M.; 
Atkins, D.; Richland, J.H.; Haddix, A. Priorities among recommended clinical preventive services. Amer. J. Prev. Med. 2001, 21, 1-9.

16. McMillen, R.C.; Winickoff, J.P.; Klein, J.D.; Weitzman, M. US adult attitudes and practices regarding smoking restrictions and child exposure to environmental tobacco smoke: Changes in the social climate from 2000-2001. Pediatrics 2003, 112, 55-60.

17. Liao, J.; Abdullah, A.S.; Nong, G.M.; Huang, K.Y.; Lin, L.D.; Ma, Z.Y.; Yang, L.; Zhang Z.Y.; Jonathan, P.W. Engaging Chinese pediatricians on secondhand smoke exposure assessment and counseling: A qualitative study. BMC Pediatrics 2014, 14, doi:10.1186/1471-2431-14-266.

18. Tanski, S.E.; Klein, J.D.; Winickoff, J.P.; Auinger, P.; Weitzman, M. Tobacco counseling at well-child and tobacco-influenced illness visits: Opportunities for improvement. Pediatrics 2003, $111,162-167$.

19. Collins, B.N.; Levin, K.P.; Bryant-Stephens, T. Pediatricians' practices and attitudes about environmental tobacco smoke and parental smoking. Pediatrics 2003, 150, 547-552.

20. Vogt, F.; Hall, S.; Marteau, T.M. General practitioners' and family physicians' negative beliefs and attitudes towards discussing smoking cessation with patients: A systematic review. Addiction 2005, 100, 1423-1431.

21. Stead, L.F.; Bergson, G.; Lancaster, T. Physician advice for smoking cessation. Cochrane Database Syst. Rev. 2008, 4, doi:10.1002/14651858.

22. Winickoff, J.P.; Buckley, V.J.; Palfrey, J.S.; Perrin, J.M.; Rigotti, N.A. Intervention with parental smokers in an outpatient pediatric clinic using counseling and nicotine replacement. Pediatrics 2003, 112, 1127-1133.

23. Zhou, J.; Abdullah, A.S.; Pun, V.C.; Huang, D.; Lu, S.; Luo, S. Smoking status and cessation counseling practices among physicians, Guangxi, China, 2007. Prev. Chronic Dis. 2010. Available online: http://www.cdc.gov/pcd/issues/2010/jan/09_0006.htm (accessed on 7 January 2015).

24. Mueller, D.T.; Collins, B.N. Pediatric otolaryngologists' actions regarding secondhand smoke exposure: Pilot data suggest an opportunity to enhance tobacco intervention. Otolaryngol. Head Neck Surg. 2008, 139, 348-352.

25. Winickoff, J.P.; Tanski, S.E.; McMillen, R.C.; Klein, J.D.; Rigotti, N.A.; Weitzman, M. Child health care clinicians' use of medications to help parents quit smoking: A national parent survey. Pediatrics 2005, 115, 1013-1017.

26. Hutchinson, S.G.; Kuijlaars, J.S.; Mesters, I.; Muris, J.W.M.; van Schayck, C.P.; Dompeling, E.; Feron, F.J.M. Addressing passive smoking in children. PLoS One 2014, 9, 93220-93229.

27. Crone, M.R.; Reijneveld, S.A.; Willemsen, M.C.; Sing, R.A. Parental education on passive smoking in infancy does work. Eur. J. Public Health 2003, 13, 269-274.

28. Butler, K.M.; Rayens, M.K.; Ashford, K.; Adkins, S.; Gombeski, B.; Britt, J.; Hahn, E.J. Smoke-free homes, strength of smoke-free law, and children in the home. Nicotine Tob. Res. 2014, 16, 485-490.

29. Sotiropoulos, A. Gikas, A.; Spanou, E.; Dimitrelos, D.; Karakostas, F.; Skliros, E.; Apostolou, O.; Politakis, P.; Pappas, S. Smoking habits and associated factors among Greek physicians. Public Health 2007, 121, 333-340. 
30. Jiang, Y.; Ong, M.K.; Tong, E.K.; Yang, Y; Nan, Y.; Gan, Q.; Hu, T.W. Chinese physicians and their smoking knowledge, attitudes, and practices. Amer. J. Prev. Med. 2007, 33, 15-22.

31. Blaine, K.; Rogers, J.; Winickoff, J.P.; Oppenheimer, S.C.; Timm, A.; Ozonoff, A. Engaging in secondhand smoke reduction discussions with parents of hospitalized pediatric patients: A national survey of pediatric nurses in the United States. Prev. Med. 2014, 62, 83-88.

32. Croghan, I.T.; Hurt, R.D.; Dakhil, S.R.; Croghan, G.A.; Sloan, J.A.; Novotny, P.J.; Rowland, K.M.; Bernath, A.; Loots, M.L.; Le-Lindqwister, N.A.; et al. Randomized comparison of a nicotine inhaler and bupropion for smoking cessation and relapse prevention. Mayo Clin. Proc. 2007, 82, 186-195.

33. Jorenby, D.E.; Leischow, S.J.; Nides, M.A.; Rennard, S.I.; Johnston, J.A.; Hughes, A.R.; Smith, S.S.; Muramoto, M.L.; Daughton, D.M.; Doan, K.; et al. A controlled trial of sustained-release bupropion, a nicotine patch, or both for smoking cessation. N. Engl. J. Med. 1999, 340, 685-691.

34. Winickoff, J.P.; Nabi-Burza, E.; Chang, Y.; Finch, S.; Regan, S.; Wasserman, R.; Ossip, D.; Woo, H.; Klein, J.; Dempsey, J.; et al. Implementation of a parental tobacco control intervention in pediatric practice. Pediatrics 2013, 132, 109-117.

35. Practical Approach to Discussing Cigarette Smoking in Pediatrics. Available online: http://www2. luriechildrens.org/ce/online/article.aspx?articleID=73 (accessed on 17 January 2015).

36. Pediatricians Cite Barriers to Tobacco Cessation Counseling. Available online: http://aapnews. aappublications.org/content/27/12/17.1.full (accessed on 17 January 2015).

37. Abdullah, A.S.; Rahman, A.S.; Suen, C.W.; Wing, L.S.; Ling, L.W.; Mei, L.Y.; Tat, L.C.; Tai, M.N.; Wing, T.N.; Yuen, W.T.; et al. Investigation of Hong Kong doctors' current knowledge, beliefs, attitudes, confidence and practices: Implications for the treatment of tobacco dependency. J. Chin. Med. Assn. 2006, 69, 461-471.

(C) 2015 by the authors; licensee MDPI, Basel, Switzerland. This article is an open access article distributed under the terms and conditions of the Creative Commons Attribution license (http://creativecommons.org/licenses/by/4.0/). 